\title{
ENTREPRENEURIAL IDEATION: EFFECTS OF MORPHOLOGY AND COMPLEXITY
}

\author{
Esparza, Antonio; Sosa, Ricardo; Connor, Andy
}

Auckland University of Technology

\begin{abstract}
Studies of product architecture identify a mirroring process between the product and the organisation. Parallel, empirical studies of effectual entrepreneurship show an accumulation of commitments between stakeholders while negotiating the features of the product in a similar fashion to product mirroring. This paper presents a study that looks at the effects of mirroring architectural complexity in early stages of entrepreneurship. The survey asked participants to interpret parametrically generated artefacts with the purpose of starting a new firm. Responses were analysed for complexity in the lexical semantic structure of ideas. Results show that the effects of artefact complexity are not as straightforward as hypothesised and provide evidence that suggests an important role of artefact morphology in entrepreneurial ideation. These findings support a model of product architecture mirroring that is filtered by design morphology.
\end{abstract}

Keywords: Mirroring process, Product architecture, Morphology, Entrepreneurship, Complexity

\section{Contact:}

Esparza, Antonio

Auckland University of Technology

COLAB

New Zealand

antonio.esparza@aut.ac.nz

Cite this article: Esparza, A., Sosa, R., Connor, A. (2019) 'Entrepreneurial Ideation: Effects of Morphology and Complexity', in Proceedings of the 22nd International Conference on Engineering Design (ICED19), Delft, The Netherlands, 5-8 August 2019. DOI:10.1017/dsi.2019.306 


\section{INTRODUCTION}

Studies of product architecture and effectuation in entrepreneurship suggest that product architecture can be leveraged within entrepreneurship to design new organizations. Product architecture refers to the structural arrangement and allocation of functions from the physical components of a designed artefact and their interfaces (Ulrich, 1995). Some studies describe a relationship between product architecture and the performance of products and firms (Christensen, 2013) and others also identify a mirroring process between the product and the organisation structures (Colfer and Baldwin, 2016). Effectuation in entrepreneurship portrays the creation of markets in a similar fashion to the theories of mirroring (Sarasvathy and Dew, 2005). In effectuation, the accumulation of stakeholder commitments around the product assembles new markets. Therefore, a flexible product design can leverage changes in product architecture with the purpose of establishing particular partnerships for the entrepreneurial venture.

This paper presents an analysis of the effects of the complexity in the product structure on entrepreneurial ideation. The study focused on the operationalization of complexity in product architecture. However, the analysis of an ideation survey suggests that design complexity may not be as straightforward as previously assumed by studies of architecture mirroring. Whilst findings indicate no effects of complexity in entrepreneurial ideation, a shared language is revealed in the interpretations of images of different complexity levels. We argue that this shared language is a consequence of the morphology of the images used in the study and discuss implications for the study of entrepreneurial ideation.

\section{BACKGROUND}

\subsection{The mirroring process of product architecture}

Early models that connect product and organization structures portrayed products as systems that solve complex functional requirements (Ulrich, 1995; Murmann and Frenken, 2006). During product design and development, management faces a coordination problem: the effective allocation of design resources for the solution of such requirements. Accordingly, those models propose breaking down complex systems in subsystems assigned to different teams, following the relationships of functional requirements. As such, a product is characterized as a system with visible or hidden interconnections of components arranged in near-decomposable subsystems that correspond to functional requirements. The modularization of complex problems generates a hierarchy of problem solving teams that defines interfaces between the design components and communication channels between teams in charge of them (Conway, 1968). Problem modularization reduces the possible interdependencies that larger and more complex systems create, thus making a more effective use of resources in design tasks (Sanchez and Mahoney, 1996). For example, modularization allows concurrent learning cycles while integral designs rely on sequential or overlapped programs. Later applications of this idea in the study of manufacturing introduced the concept of product architecture and began studying the effects on product, design team, and firm performance.

Studies of industrial dynamics have addressed the effects of product architecture from a broader perspective. Based on frameworks that describe innovation cycles, researchers have explored the degree of change in performance dimensions such as design knowledge, architecture, or market maturity (Christensen and Rosenbloom, 1995; Henderson and Clark, 1990; Murmann and Frenken, 2006). It has been suggested that early architectural subdivisions of artefact functions are gradually mirrored to the structure of the industry and its participants i.e. suppliers, distributors, regulators, etc. (Colfer and Baldwin, 2016). Christensen and Rosenbloom (1995) notice the presence of a "value network", or a network of stakeholders that become aligned through the common understanding of performance dimension that is related to a particular product architecture. This suggests that technologies are situated in the common understanding of product performance and rely on the interpretation that stakeholders bring forward in specific contexts.

\subsection{Effectual entrepreneurship}

Entrepreneurship research describes the creation of business ventures as either a process of discovery or as process of creation of new business opportunities (Alvarez and Barney, 2007). Theories of 
opportunity creation view entrepreneurs as enacting the context they are immersed in, i.e., effectual entrepreneurship (Sarasvathy, 2008). According to this view, opportunities are built when entrepreneurs make use of their resources at hand (information, means, and partnerships) to achieve personal goals. Effectual entrepreneurship uses design to govern ventures locally and contingently, and by creating enduring systems that are near decomposable (Sarasvathy, 2003). Effectuation portrays market creation as a process where entrepreneurs control the design of the artefacts that compose the business venture.

The mechanics of market creation are explained as a collection of transactions shaped by the design of effectual contracts (Sarasvathy and Dew, 2005). In an effectual contract, the expert entrepreneur ideates and evaluates possible courses of action according to the means at hand. During the exploration of such options, entrepreneurs interact with possible stakeholders (suppliers, distributors, customers, etc.). An effectual contract appears when two stakeholders negotiate to commit means, in order to move the venture forward. Product architecture becomes central in the effectual contract since the design of the product is negotiated in order for the parts to work with it (Sarasvathy and Dew, 2005). Parallel to the mirroring process, Sarasvathy \& Dew (2005) explain that the accumulation of these contracts expands the network of stakeholders that interact with the business venture, thus creating a market. Hence, Sarasvathy also highlights the importance of a common understanding in the semantics of the design of a market structure (Sarasvathy, 2004).

We propose to connect the study of product architecture and entrepreneurship. We also propose that this dual view of the innovation cycle provides a framework that links the design of a product architecture to the creation of markets. The rationale behind the articulation of technology cycles and entrepreneurship suggests that the complexity of a product's architecture is a salient factor that structures the negotiations between stakeholders in the creation of effectual contracts. Therefore, the design of a product's architecture represents the first step in the mirroring process between product architecture and market institutions.

\subsection{Product complexity}

Suh (2005) defines complexity in design as the measure of uncertainty in achieving a functional requirement. The complexity in the implementation of a particular product architecture includes the definition of the functional requirements and the fabrication of the configuration ( $\mathrm{Lu}$ and Suh, 2009). Inborn (or functional) complexity is built into the delineation of the artefact functions and thus is present in the original problem space of the design. Consequently, any artefact in the same category shares the same inborn complexity because it shares the same functional requirements. On the contrary, acquired complexity is the result of design decisions that balance the initial requirement with the available resources and manufacturing processes. Inborn system complexity has been the focus of most of product architecture studies (Browning, 2001; Sosa et al., 2004).

\section{METHOD}

We view entrepreneurial ideation as the conception of possible courses of action in the creation of new ventures. Research on entrepreneurial ideation focuses on social and cognitive perspectives that describe it as a problem solving device (Gemmell et al., 2012; Gundry et al., 2016). Yet, the theories of effectuation and mirroring suggest that this ideation mechanism relies on artefact exploration and interaction. Entrepreneurship mirroring suggests that within entrepreneurial ideation, the exploration of the product architecture informs the ideation of possible paths that the business venture can use to incorporate new stakeholders. Thus, product architecture informs the creation of the early connections between components that will get mirrored into the firm and the industry. We consider that entrepreneurial ideation interprets the product as part of the resources used to create possible opportunities for effectuation. Within the interpretation, the inborn complexity of the product structure is copied into the structure of the imagined courses of action; the number of elements and the interrelation between them. Therefore, the purpose of this study is to explore the effects of product complexity in the mirroring process within entrepreneurial ideation o confirm the link between product and organization structures in the beginning of the business venture. Based on the theories of architectural mirroring, we hypothesize the following:

$\mathrm{H}$. The complexity of product architecture has a mirroring effect on the complexity of the results of entrepreneurial ideation. 
Business venturing is not exclusive to expert entrepreneurs or designers that have full knowledge of design processes and tools. Hence, the study focused the ideation process around mental imagery. The interaction between visual and mental representations is used in creative cognition research (Finke, 1996; Kudrowitz and Dippo, 2013). The exercise was designed as a survey that presented one of ten images of parametrically generated artefacts divided into five different categories of complexity and two categories of symmetry. The artefact images were distributed randomly through an online survey to 308 participants through Amazon MTurk (Cunningham et al., 2017). The instrument asked participants to mentally design a commercial application of the shape and complete statements about the product, the name and core values of the firm, its customers, and the involved stakeholders. As mentioned, there is no evidence that suggests that designers of product architecture in entrepreneurial ventures need to be expert designers (Davidsson, 2007; Gartner, 1988), therefore the participant selection criteria looked for people with interest in entrepreneurship, with an education degree of high school or higher, and between the ages of 18 to 64. These requirements are used by the Global Entrepreneurship Monitor to study entrepreneurial activity (Global Entrepreneurship Research Association, 2017).

\subsection{Survey design}

\subsubsection{Image input}

Visual imagery has been used as a mechanism for generation and exploration of alternative solutions for creative tasks (Finke, 1996; Jankowska and Karwowski, 2015). Our survey used a generative design algorithm that created randomized configurations of rounded volumes with a desired number of components. The algorithm builds such components by creating an initial revolved body of randomized dimensions and drawing a grid of points in its circumference and transverse $\mathrm{X}$ and $\mathrm{Y}$ axes. It continues by selecting a random number of points as centres of for the creation of new bodies. The process repeats itself until the desired number of components is fulfilled. Five levels of complexity were selected, from two to six components, in order to create enough difference between the extreme stimuli, and at the same time avoid over-complicated images that became difficult to interpret. Symmetric and asymmetric images were introduced for variable control purposes (Figure 1).

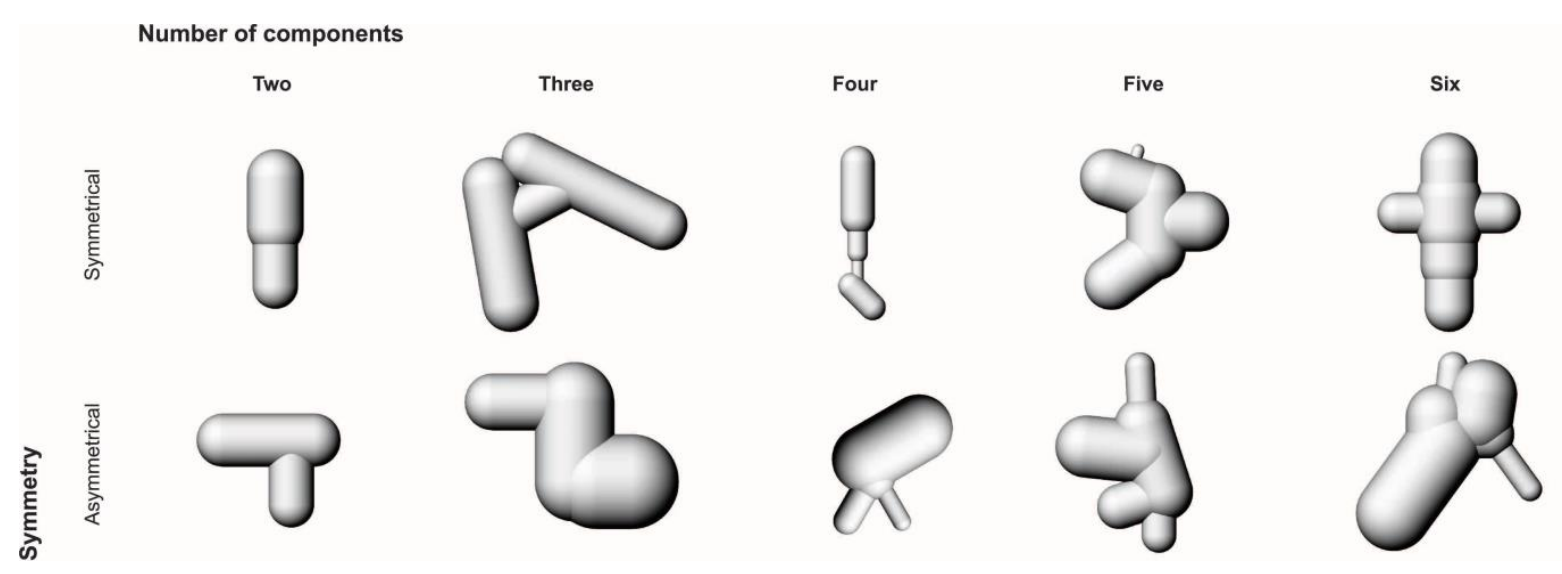

Figure 1. Collection of images used in the survey

\subsubsection{Survey statements}

The survey was composed by 13 statements to be completed by participants. Each statement was followed by a short instruction to aid completion. The statements focused on topics that concern business modelling.

1. The name of the product is (My product is a kind of (describe a category)...

2. describe a name)...

3. My product is designed to assist (describe the customer that will buy it)...

4. My product helps customers to (describe the goals of the costumer)...

5. My product fulfils these goals by (describe how the product works)...

6. My product competes against other products like (describe other product categories that could compete with your product)...

7. My product is better than its competitors because (describe the traits or qualities that make it the 
best option for your customers)...

8. The name of my brand is (describe a name)...

9. My brand is designed to reach (among your customers, describe the brand lead users/fans)...

10. My customers believe in (describe the values that your customers believe in)...

11. My brand partners with (describe categories of other firms you could partner with)...

12. Together with these partners we (describe the activities you could do with your partners)...

13. Therefore, my brand delivers our products through (describe your distribution channels or how are your products delivered)...

\subsubsection{Network evaluation and classification}

Participant responses were portrayed as networks that showed the lexical semantic relationships between the words in the response. As a network system, its complexity can be compared to the complexity of the input product architecture. To confirm the hypothesis, more complex product architectures should entail more, or more interrelated lexical semantic relationships. These lexical semantic networks were recreated with a Natural Language Processing (NLP) algorithm (Bird et al., 2009; NLTK Project, 2017). The algorithm searches each unique word within a pool of words in the WordNet database (Fellbaum, 2005) to find lexical-semantic connections. The search looked for relationships that included synonymy, antonymy, hypernymy, hyponymy, meronymy, metonymy, holonymy, homonymy and semantic entailments. The collection of connections was used to portray a network for each pool of words. Hence, each word pool was evaluated for the length of responses, the frequency of words, and the lexical depth of each word. Additionally, each corresponding network was measured for number of nodes, number of edges, number of nodes in contact with one or more words in the original text, and density of the network as complexity metrics. In order to optimize the classification with WordNet, the full text of answers was parsed and cleaned by removing stop-words, and functional words. Additionally, words that described character and actions that were not part of categorical descriptions were removed. The remaining words were grouped in pools for their analysis. With the objective of studying the effects of complexity at different scopes, the pools were assembled at four levels of aggregation: words in the same sentence (sentence), words in the same concept (concept), words originated in the same sentence for all the concepts regarding the same image (topic), and all words regarding an only image (image).

\section{RESULTS}

\subsection{Survey participants}

The survey ran for five days for workers who had at least received a High School degree. Participants were offered a compensation of \$2.00 USD for their participation. A total of 308 responses were valid from 595 received. Invalid responses included incomplete answers, automatically filled with random characters, or words without sense (repetitions of the survey items or sentences made from the same word). All surveys were filled out in the United States. The average time for survey completion was 8:49 minutes. Participant profiles show a higher percentage of respondents with tertiary education and native English speakers (Table 1).

Table 1. Distribution of participants age, education level, and language

\begin{tabular}{|c|c|c|c|c|c|c|c|c|}
\hline Age & & & Education degree & & & Language & & \\
\hline & Frequency & Percent & & Frequency & Percent & & Frequency & Percent \\
\hline $18-24$ & 26 & $8.4 \%$ & High School & 36 & $11.7 \%$ & Native english speaker & 303 & $98.4 \%$ \\
\hline $25-29$ & 61 & $19.8 \%$ & Diploma & 56 & $18.2 \%$ & Foreign english speaker & 6 & $1.9 \%$ \\
\hline $30-34$ & 54 & $17.5 \%$ & Bachelor Degree & 134 & $43.5 \%$ & Total & 308 & $100.0 \%$ \\
\hline $35-39$ & 50 & $16.2 \%$ & Postgraduate Diploma & 6 & $1.9 \%$ & & & \\
\hline $40-45$ & 32 & $10.4 \%$ & Postgraduate Degree & 76 & $24.7 \%$ & & & \\
\hline 45-older & 85 & $27.6 \%$ & Total & 308 & $100.0 \%$ & & & \\
\hline Total & 308 & $100.0 \%$ & & & & & & \\
\hline
\end{tabular}

\subsection{Concept content}

Concepts were classified with the purpose of understanding a complete picture of the retrieved content. First, each concept was tagged with the most specific instantiation of object, personal identity, 
and organization identity mentioned by the participant. Second, each tag was related to any other tag that represented a superordinate or subordinate version of it. Next, a network of concepts was assembled by representing the relationships between tags with edges amongst the concept nodes. Finally, the network was divided in subsystems using a modularization algorithm (Blondel et al., 2008). The resulting network shows 10 modules that gathered concepts in semantic fields (Table 2). These semantic fields seem not to represent traditional superordinate categories of ideas, but themes that are more situational.

Table 2. Concept content distribution

\begin{tabular}{|l|l|}
\hline Theme & $\begin{array}{l}\text { Percent of } \\
\text { Nodes }\end{array}$ \\
\hline Games and Toys & $22.73 \%$ \\
\hline Gadgets and Electronics & $18.51 \%$ \\
\hline Massagers, Sports and Camping & $12.34 \%$ \\
\hline Pharmacy and Home Repairs & $10.71 \%$ \\
\hline Tools and Furniture & $7.79 \%$ \\
\hline Home Shopping Products & $7.79 \%$ \\
\hline Elderly Assistance & $7.47 \%$ \\
\hline Hand Graspable and Flexible & $6.82 \%$ \\
\hline Stress Balls and other Squeezeables & $5.52 \%$ \\
\hline AChilly Pack for Injuries (stand alone idea) & $0.32 \%$ \\
\hline
\end{tabular}

\subsection{Data analysis}

The different levels of aggregation evaluated 4,004 sentences, 308 concepts, 130 topics (13 per image), and 10 image word collections. Means differences in every metric were tested using a single ANOVA test for the number of components and symmetry variables in each level of aggregation. The results were counterintuitive since no significant differences were found in any metric at any aggregation level. No variation in any statistic was found to support complexity effects, thus rejecting the hypothesis. Moreover, within each examination, the relationship between the different component numbers did not present a pattern that could be associated with increasing numbers of components or symmetry. The relationships between statistics amongst the different numbers of components also differed from one level of aggregation to another.

Yet, in the comparison of the descriptive statistics between the different levels of aggregation, statistics for number of nodes, contact nodes, and density showed unexpected results. According to the properties of a growing network, the introduction of new nodes with new edges increases the number of possible connections between them exponentially. Thus, as density is measured with reference to possible connections between all the nodes in the network, the mean density of networks shows a decrement for every bigger aggregation level (Figure 2). Nevertheless, the number of contact nodes follows a different path and increments every time more words are incorporated despite the increment in node population (Figure 3). In a similar, unexpected fashion, the total number of evaluated nodes decreased from the sentence level with bigger levels of aggregation (Figure 4). A close examination of the data showed that the number of total evaluated words decreased, because same words in different sentences were considered as one by the NLP algorithm when all sentences were incorporated in a bigger pool. The repetition of words was an obvious reason that explained the reduction of evaluated words when transitioning from the sentence to the concept level where the same participant described the same concept. However, the repetition of words and the increased number of contact entailments in the topic and image levels suggested the presence of similar patterns in lexical-semantic relationships amongst participants. 


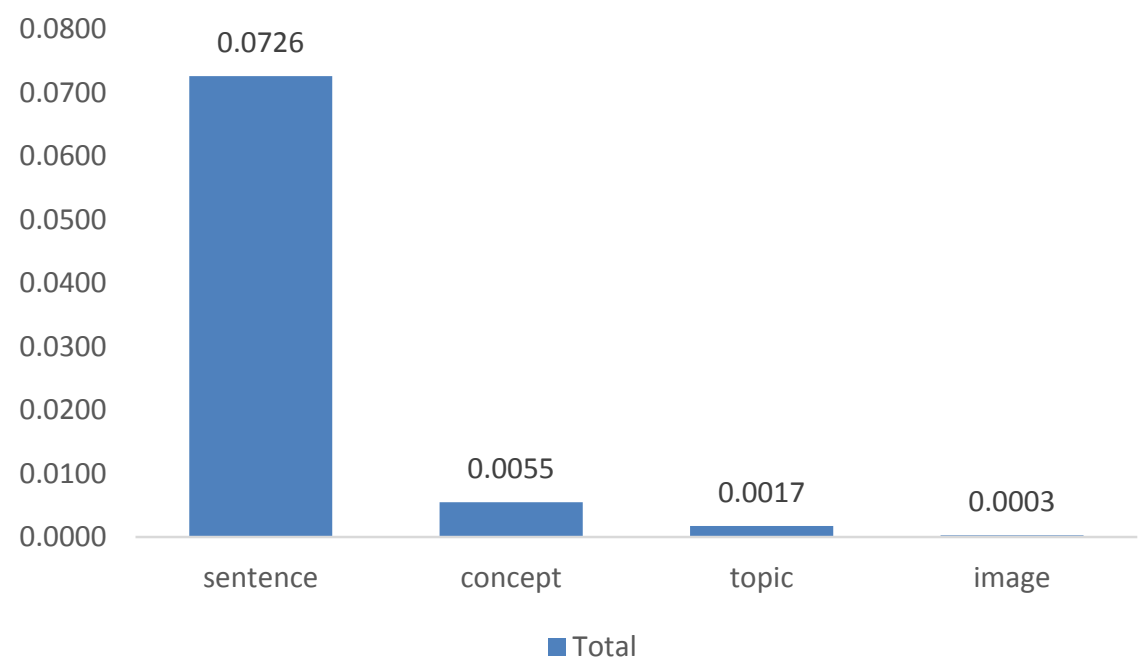

Figure 2. Mean density in networks at different levels of aggregation

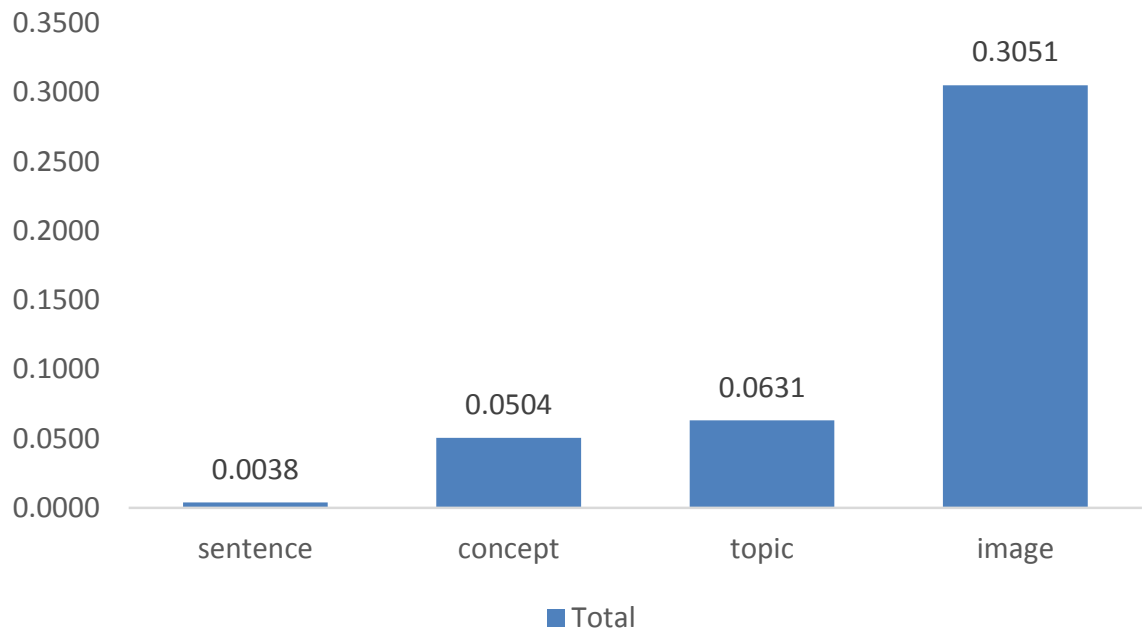

Figure 3. Mean contacts in networks at different levels of aggregation

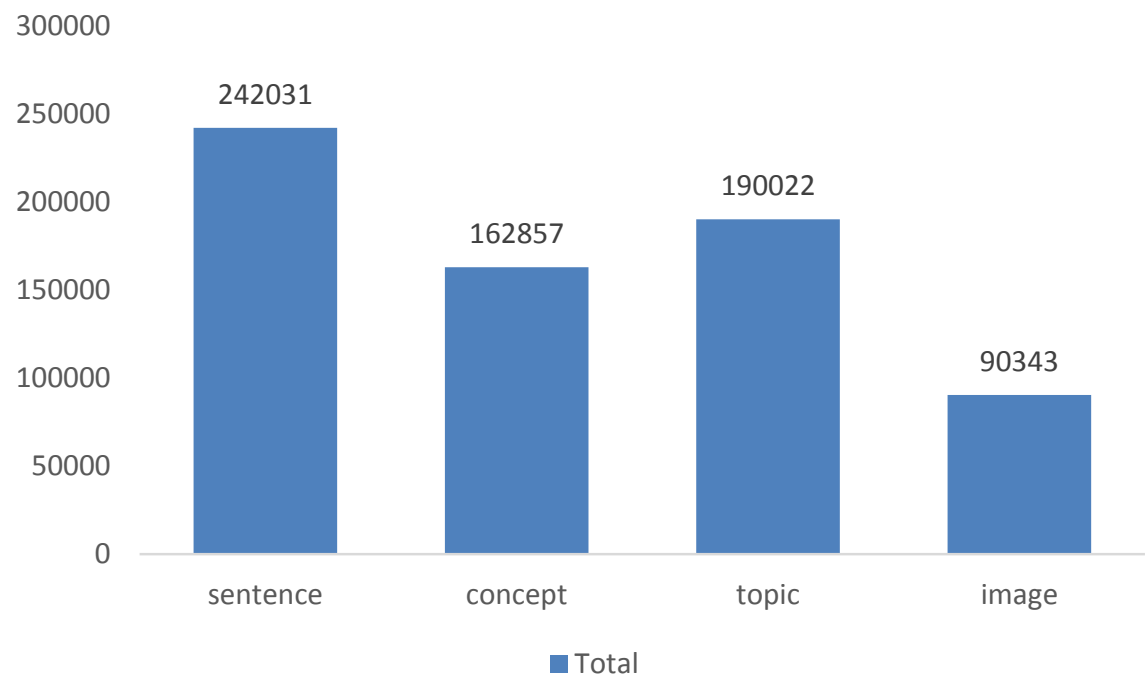

Figure 4. Total evaluated nodes at different levels of aggregation 
A second analysis was undertaken with the purpose of looking at the repetition of words in bigger pools. The complete set of words from all responses was evaluated by using the same algorithm to generate a network that describes the complete universe of all the survey questions. Each word created a node that was tagged according to the number of images, themes, and questions that it was related to, the in-degree score, and closeness centrality in the network. Nodes were divided between original nodes in text and contact entailments between them. The network density and diameter were also evaluated.

The generated network contained 12,598 nodes, including both original $(\mathrm{N}=2,218)$ and contact nodes $(\mathrm{N}=10,380)$. A set of fitness chi-square tests were used to examine the distribution of these nodes amongst the number of manually coded themes they appeared in. A fitness examination with the themes would prove the presence of common interpretations. The tests show that original nodes are significantly distributed in any of these classifications. Two extremes of the distribution cluster most of the words, where 1,129 words (50.9\%) are related to just one theme compared to 571 words (25.7\%) that are shared in all themes. These distributions present strong effects from theme modularity (Cramer's $\mathrm{V} \approx 0.5)$. On the contrary, contact nodes present an opposite concentration of $48(0.4 \%)$ words that are related to a theme and mostly to one or two images. The other extreme is occupied by 6,464 contact words $(62.3 \%)$ that are related to all themes and almost all questions and images. Again, the effects of this distribution are strong (Cramer's $\mathrm{V} \approx 0.5$ ).

In-degree scores were tested, since they indicate the concentration of relationships from other nodes in the network, contrary to out-degree that depends on the thesaurus definition of each word. ANOVA tests show that the extremes, in both original and contact nodes, that are in touch with more themes, concentrate a significantly higher in-degree of connections in the network $(\alpha \approx 0.0)$. Therefore, in both original and contact nodes, words that are shared between groups also concentrate increased numbers of relationships.

\section{DISCUSSION}

The results of this study lead us to re-examine the model of architectural mirroring that focuses on functional allocation and structural complexity. It is important to evaluate the influence of unaccounted variables in the experiment. For instance, individual differences can influence the generation of ideas based on personal backgrounds (e.g. participants 45 years and older that imagine products for children). However, the randomization of the survey platform, the topic level statistics and the fact that the shared vocabulary covers every image, discards this variable, at least as the most influential. Alternatively, another unaccounted variable that could explain such results is the morphology of the presented artefact. In spite of the intended "neutrality" in the design of the algorithm, the different images presented carry common visual properties (colour, texture, etc.). Neither in studies of architectural mirroring nor in mental imagery studies, have these features of design morphology been accounted for.

Secondly, the results prioritize the semantic dimension of product morphology instead of the structure of product architecture in the creation of new markets. The results show a semantic network that can be found within the concept of the value network (Christensen and Rosenbloom, 1995). Additionally, this semantic network can also be articulated with the model of the effectual contract (Sarasvathy and Dew, 2005) as the design space for the enactment of the product, and as a resource for the entrepreneur. Hence, artefact morphology can be considered an unaccounted externality, that shapes the available semantic relationships in the manipulation of a particular product or technology. This suggests that the creation of new markets entails a process of technological interaction, which can be translated as a process of "design as exploration", instead of "design as search" (Dorst and Cross, 2001). Therefore, we speculate here that architectural mirroring affects the perception of stakeholders as much as the morphology of the involved technology allows it to. Consequently, we propose the study of morphology as a filter or boundary of entrepreneurial ideation that happens before functional mirroring. Instead, product architecture and its mirroring might be determined within the boundaries already set by product morphology.

The unexpected quality of these results highlights the limitations of the study. We propose that a further examination of artefact morphology should be based on a wider semantic dataset that does not rely forcefully on the lexicon, as WordNet does. More specialized semantic databases could be assembled from the specific instances of business transactions such as early contracts, entrepreneurial 
pitch decks, product marketing, or landing pages. Similarly, the selection of the visual language has a great potential for operationalization and analysis. Altogether, this study questions the assumptions of complexity mirroring in the creation of new markets and the introduction of new products. At the same time, it creates an interface between design and entrepreneurship research that can articulate the effects of design morphology.

\section{REFERENCES}

Bird, S., Klein, E. and Loper, E. (2009), "Natural Language Processing with Python: Analyzing Text with the Natural Language Toolkit”, 1 edition. ed. Cambridge Mass, O’Reilly Media, Beijing.

Blondel, V.D., Guillaume, J.-L., Lambiotte, R. and Lefebvre, E. (2008), "Fast unfolding of communities in large networks", J. Stat. Mech. Theory Exp. 2008, p. 10008. https://doi.org/10.1088/1742-5468/2008/10/P10008

Browning, T.R. (2001), "Applying the design structure matrix to system decomposition and integration problems: a review and new directions”, IEEE Trans. Eng. Manag. Vol. 48, pp. 292-306. https://doi.org/10.1109/17.946528

Christensen, C. (2013), “The Innovator's Dilemma: When New Technologies Cause Great Firms to Fail”. Harvard Business Review Press.

Christensen, C.M. and Rosenbloom, R.S. (1995), “Explaining the attacker's advantage: Technological paradigms, organizational dynamics, and the value network". Res. Policy Vol. 24, pp. 233-257. https://doi.org/10.1016/0048-7333(93)00764-K

Colfer, L.J. and Baldwin, C.Y. (2016), “The mirroring hypothesis: theory, evidence, and exceptions”, Ind. Corp. Change Vol. 25, pp. 709-738. https://doi.org/10.1093/icc/dtw027

Conway, M.E. (1968), “How do committees invent?”, Datamation Vol. 14, pp. 28-31.

Cunningham, J.A., Godinho, A. and Kushnir, V. (2017), “Can Amazon's Mechanical Turk be used to recruit participants for internet intervention trials? A pilot study involving a randomized controlled trial of a brief online intervention for hazardous alcohol use", Internet Interv. Vol. 10, pp. 12-16. https://doi.org/10.1016/j.invent.2017.08.005

Davidsson, P. (2007), "Method challenges and opportunities in the psychological study of entrepreneurship", Psychol. Entrep. p. 287323.

Dorst, K. and Cross, N. (2001), “Creativity in the design process: co-evolution of problem-solution”, Des. Stud. Vol. 22, pp. 425-437. https://doi.org/10.1016/S0142-694X(01)00009-6

Finke, R.A. (1996), "Imagery, Creativity, and Emergent Structure”, Conscious. Cogn. Vol. 5, pp. 381-393. https://doi.org/10.1006/ccog.1996.0024

Gartner, W.B. (1988), “Who Is an Entrepreneur?” Is the Wrong Question”, Am. J. Small Bus. 12, pp. 11-32. https://doi.org/10.1177/104225878801200401

Gemmell, R.M., Boland, R.J. and Kolb, D.A. (2012), “The Socio-Cognitive Dynamics of Entrepreneurial Ideation. Entrep", Theory Pract. Vol. 36, pp. 1053-1073. https://doi.org/10.1111/j.15406520.2011.00486.x

Global Entrepreneurship Research Association, (2017), “Global Entrepreneurship Monitor Global Report 2016/17”, Global Entrepreneurship Monitor.

Gundry, L.K., Ofstein, L.F. and Monllor, J. (2016), "Entrepreneurial Team Creativity: Driving Innovation from Ideation to Implementation", J. Enterprising Cult. Vol. 24, pp. 55-77. https://doi.org/10.1142/S0218495816500035

Henderson, R.M. and Clark, K.B. (1990), “Architectural Innovation: The Reconfiguration of Existing Product Technologies and the Failure of Established Firms". Adm. Sci. Q. Vol. 35 No. 9. https://doi.org/10.2307/2393549

Jankowska, D.M. and Karwowski, M. (2015), "Measuring creative imagery abilities”, Front. Psychol. Vol. 6. https://doi.org/10.3389/fpsyg.2015.01591

Kudrowitz, B. and Dippo, C. (2013), "When does a paper clip become a sundial? Exploring the progression of originality in the alternative uses test", J. Integr. Des. Process Sci. Vol. 17, pp. 3-18.

Lu, S.C.-Y. and Suh, N.-P. (2009), "Complexity in design of technical systems", CIRP Ann. - Manuf. Technol. Vol. 58, pp. 157-160. https://doi.org/10.1016/j.cirp.2009.03.067

Murmann, J.P. and Frenken, K. (2006), "Toward a systematic framework for research on dominant designs, technological innovations, and industrial change”. Res. Policy. Vol. 35, pp. 925-952. https://doi.org/10.1016/j.respol.2006.04.011

NLTK Project (2017), "Natural Language Toolkit - NLTK 3.3 documentation [WWW Document]", URL http://www.nltk.org/ (accessed 9.10.18).

Sanchez, R. and Mahoney, J.T. (1996), "Modularity, flexibility, and knowledge management in product and organization design”, Strateg. Manag. J. Vol. 17, pp. 63-76. https://doi.org/10.1002/smj.4250171107

Sarasvathy, S.D. (2004), "Making It Happen: Beyond Theories of the Firm to Theories of Firm Design. Entrep", Theory Pract. Vol. 28, pp. 519-531. https://doi.org/10.1111/j.1540-6520.2004.00062.x 
Sarasvathy, S.D. (2003), "Entrepreneurship as a science of the artificial”, J. Econ. Psychol. Vol. 24, pp. $203-220$.

Sarasvathy, S.D. and Dew, N. (2005), "New market creation through transformation", J. Evol. Econ. Vol. 15, pp. 533-565. https://doi.org/10.1007/s00191-005-0264-X

Sosa, M.E., Eppinger, S.D. and Rowles, C.M. (2004), “The Misalignment of Product Architecture and Organizational Structure in Complex Product Development”. Manag. Sci. Vol. 50, pp. 1674-1689. https://doi.org/10.1287/mnsc.1040.0289

Suh, N.P. (2005), "Complexity: Theory and Applications”, Oxford University Press.

Ulrich, K. (1995), "The role of product architecture in the manufacturing firm”. Res. Policy Vol. 24, pp. 419440. https://doi.org/10.1016/0048-7333(94)00775-3 